\title{
ASO Visual Abstract: Predictors for Implant Rupture in Two- Stage Tissue Expander-Based Breast Reconstruction-A Retrospective, Cohort Study
}

Juyoung Bae, MD, Byung-Joon Jeon, MD, Goo-Hyun Mun, MD, Sa Ik Bang, MD, Jai Kyong Pyon, MD, and Kyeong-Tae Lee, MD

Department of Plastic Surgery, Samsung Medical Center, Sungkyunkwan University School of Medicine, Seoul, Korea

Despite increasing popularity of two-stage tissue expander/implant breast reconstruction, only a paucity of studies have evaluated the risk factors of implant rupture with a focus on cases using this modality. Based on the analysis of approximately 800 cases, our study (https://doi. org/10.1245/s10434-021-10773-w) suggested several operation-related variables, including interval between the first- and second-stage operation and implant type, appear to be associated with implant rupture in two-stage prosthetic breast reconstruction.

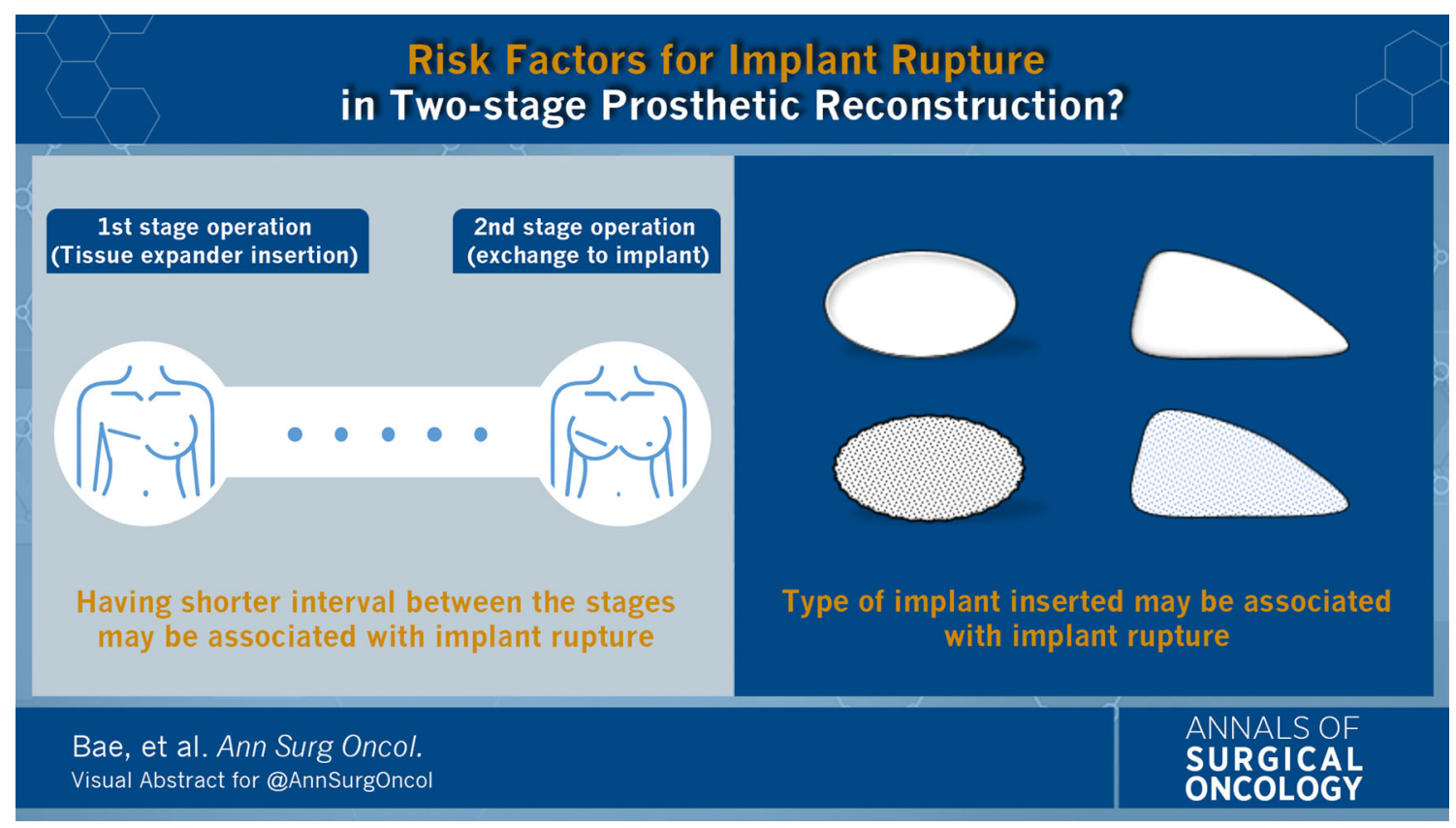

(C) Society of Surgical Oncology 2021

Published Online: 9 October 2021

J. K. Pyon, MD

e-mail: pspriest.pyon@samsung.com

K.-T. Lee, MD

e-mail: skymaker26.lee@samsung.com
DISCLOSURE None of the authors have a financial interest in any of the products, devices, or drugs mentioned in this manuscript.

Publisher's Note Springer Nature remains neutral with regard to jurisdictional claims in published maps and institutional affiliations. 